\title{
Elefantes de vapor. El patrimonio de la modernidad y su dimensión territorial en el valle del Guadalquivir
}

Plácido González Martínez,

Marta Santofimia Albiñana, Centro

de Documentación y Estudios del IAPH
Durante su estancia en Holanda, desde 1629 a 1649, René Descartes pudo conocer y admirar de primera mano la labor de constructores de diques, que arrebatando terreno al mar, creaban un nuevo territorio, fértil y productivo, ofreciendo un ejemplo temprano de la fascinación por la tabula rasa como referente constante de la modernidad desde el siglo XVII hasta nuestros días. Como mostraría en su Discurso del método (1637), la Razón, atrincherada tras las barreras artificiales que la cultura y la ciencia habian erigido a lo largo de la historia, podia hacer frente a la naturaleza, someterla y utilizarla para construir un nuevo mundo.

Las referencias que proporcionaban los Países Bajos como territorio artificial presentaban a la tabula rasa no como un proceso destructivo sino como acto creativo de primer orden, por el cual la relación entre técnica y naturaleza, lejos de pensarse en términos de oposición, se planteaba desde la complementariedad y la mejora mutua. Es por ello que a inicios del siglo XX, el dominio y control de la fuerza del agua cobraran un especial significado a ojos de los arquitectos de la modernidad, que fascinados por la capacidad de transformación de la ingeniería, siguieron mirando hacia Holanda, concretamente a la obra hidráulica de mayor envergadura que se emprendia en Europa en aquellos momentos: la desecación del Zuidersee, iniciada en 1927 con la construcción de un dique de treinta y dos kilómetros de longitud, como primer paso para la desecación del estuario al que se asomaba la ciudad de Amsterdam para su posterior conversión en tierras cultivables y urbanizables.

El perfeccionamiento de la naturaleza no se detenía en el propósito de la creación de espacio vital para la cultura, sino que, como ocurrió en los Estados Unidos a partir de 1933 con la creación de la Tennessee Valley Authority (TVA), iba más allá, apostando por transformar la economía agrícola a través de la racionalización de los riegos y la creación de una red de canalizaciones que, a modo de segunda naturaleza superpuesta sobre el territorio, racionalizase una actividad tradicionalmente expuesta a la ávida sobreexplotación humana y a los vaivenes caprichosos del clima.
Si bien el control y la racionalización del agua ya habían sido puestos en práctica por la estrategia civilizadora de Roma más de dos milenios antes, el proyecto moderno para la transformación del territorio rural presenta además la particularidad de la producción de energía. Antes incluso que la TVA, las autoridades de la recién fundada Unión Soviética localizaron en ésta un campo de actuación preferente cuyas líneas rectoras quedaron delineadas con la redacción del plan GOELRO (1920) para la electrificación de Rusia. Preveian así la construcción de diez grandes plantas hidroeléctricas que suministrasen la energía suficiente para orquestar la deseada disolución de la ciudad en el campo que imaginaron con brillantez los arquitectos desurbanistas y que impulsó algunas de las investigaciones urbanísticas más interesantes y atrevidas que vieron el siglo pasado.

De manera intencionada, el recorrido por el primer tercio de siglo a través de Holanda, los Estados Unidos y la Unión Soviética, ilustra la suma de los propósitos del control del agua, la mejora de la agricultura y la producción de energía, sirviéndonos la posibilidad de leer un propósito de modernización territorial de indiscutible valor patrimonial contemporáneo, indiferente a la dispersión geográfica y al diferente sesgo politico de sus promotores. A través de la siguiente ruta habremos de mostrarlo como espíritu de los tiempos a nivel global cuya manifestación en el valle del Guadalquivir resulta tan ejemplar como reveladora.

En el caso de España, la experiencia fue resultado de una gestación que comenzó en el siglo XIX cuando las propuestas sobre política hidráulica de Joaquín Costa trazaron las líneas generales de la modernización agraria e industrial del país. Tras la constitución de las Confederaciones Hidrográficas en 1926, el impulso político se dotó de las herramientas administrativas necesarias para emprender la planificación hidrológica, la gestión de los recursos acuiferos y la construcción de las infraestructuras, que por encima de vicisitudes políticas, continuaron a lo largo de la Segunda República y la dictadura franquista convirtiéndose en uno de los pilares del desarrollo económico y social del país. 

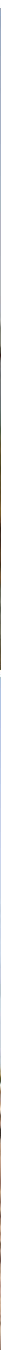

Escuela nacional de niños. Villafranca de Córdoba (1928)

Foto: Juan Carlos Cazalla, IAPH

Escuela nacional de niñas. Villafranca de Córdoba (1933).

Foto: Juan Carlos Cazalla, IAPH

Fábrica azucarera San Fernando y destilería Los Rosales. Tocina. (1925).

Foto: Juan Carlos Cazalla, IAPH

Fábrica de harinas y tejidos de yute Sánchez Pastor. Peñaflor (1926).

Foto: Juan Carlos Cazalla, IAPH

hubo de compatibilizarse con el escaso espacio disponible para su construcción, lo que determinó que se integrara la central en la pantalla de la presa a modo de prolongación del paramento en expresionistas formas. La presa, de tipo de gravedad, planta curva y sección triangular, cuenta con una altura de 90 metros sobre el cauce y una longitud de 200 metros. En su coronación se sitúa el torreón almenado que aloja las compuertas y que se abre a la cara aguas abajo con un balcón en ménsula, quedando el conjunto revestido de piedra con la clara intención de integrarlo en el entorno.

Aguas abajo encontramos el salto y la central de Encinarejo (1928), construidos para aprovechar el desnivel de 92 metros del río Jándula hasta su confluencia con el Guadalquivir. La central se adosa, al igual que en el caso anterior, a la pantalla de la presa que esta vez responde a la tipología de presa vertedero de 30 metros de altura. El edificio de turbinas, de planta rectangular, está desplazado hacia la margen derecha quedando el conjunto igualmente revestido con sillares de granito. Su construcción se inicia en 1928, aprovechando las infraestructuras que se estaban utilizando aguas arriba, y se pone en servicio a finales de 1930, cuatro meses después de la presa del Jándula.
Como parte de la estrategia de acumulación y distribución de agua que seguía la política hidráulica, la colonización del valle del Guadalquivir se basó en el trazado de una red de canales que servian de infraestructura base para el desarrollo de cultivos de regadío. Esta nueva actividad agricola requería de la construcción de nuevos pueblos, que eran objeto de una experiencia singular de adaptación de la arquitectura popular a los dictados de normalización que la modernidad imponía, y que constituyen por sí mismos un valor patrimonial de primer orden, manifestado de forma ejemplar en el pueblo de Llanos del Sotillo (1956), obra de los arquitectos José Antonio Corrales y Juan Ponce Bago.

Llanos del Sotillo se sitúa junto a la carretera nacional IV, afirmando su condición icónica con la torre de la iglesia como hito que señala el corazón del pueblo. Un espacio central que, en la más pura línea de las investigaciones desarrolladas por los CIAM a partir del VIII Congreso de Hoddesdon (1951), quedaba caracterizado por la construcción de una poderosa infraestructura social que Corrales resolvió con excepcional sencillez: un edificio lineal elevado sobre pilotis, que contenía las viviendas para los maestros, la escuela, y la iglesia, dejando un espacio público cubierto de excepcional belleza. Es de señalar el cuidado de Corrales por lo 
cívico, evidenciado en el sensible trazado de las calles peatonales, intimamente vinculadas al desarrollo de las viviendas, que se alzan sobre el espacio público creando una sutil celosía arquitectónica, espacio de luces y sombras y de intensa actividad comunitaria que constituye un logro urbanístico de excepcional calidad.

La continua demanda de energía de la industria cordobesa en el primer tercio del siglo XX fue el origen del salto y la central eléctrica de El Carpio (1925). Situados en un tramo del río de relativa pendiente, el conjunto aprovecha la entrada y la salida de un meandro para separar la presa y la central incorporando 6 metros de desnivel al salto. La presa dispone de dos estribos a ambas márgenes del río y cinco contrafuertes que soportan las seis compuertas móviles, y en su margen derecha se alza la torreta de control sobre un arco de herradura con alfiz en forma de puerta sobre el puente, quedando en su conjunto revestida de bloques de piedra. El edificio de la central, premiado con la medalla de oro en la Exposición Internacional de las Artes Decorativas de Paris en 1925, es de planta rectangular, destacando por su belleza el remate de la cubierta de la sala de turbinas, compuesto por cúpulas sasánidas. Como ingenioso remate, aparece la cabeza de un elefante como ménsula del balcón que se asoma aguas abajo que, en palabras de Fernández-Shaw, "simbolizaria la energía de los 10000 caballos de fuerza de la Central, una nueva medida de fuerza electromotriz sería el elefante de vapor", y que sirve de muestra de la frescura ecléctica del arquitecto.

Tras la central del Carpio, el río endereza su curso, apuntando hacia la población de Villafranca de Córdoba, que sirve dos piezas de arquitectura del racionalismo de excepcional calidad, fruto de los programas de equipamiento social de la dictadura de Primo de Rivera. Situada en el corazón del pueblo, la Escuela Nacional de Niños (1928), proyectada por José Joaquín González Edo, constituye un manifiesto de modernidad; evidenciando la sencillez de la disposición de las aulas que reciben iluminación natural a través de los generosos huecos horizontales en contraste con el volumen vertical de la torre de ladrillo, hito urbano fácilmente reconocible desde la calle Alcolea a la que se abre.

De mayor pureza compositiva, la Escuela Nacional de Niñas (1929); construida por el mismo González Edo sólo un año después de la Escuela de Niños, aprovecha la libertad que le confiere una posición periférica menos comprometida, que permite ofrecer respuestas enormemente diversas a los condicionantes del programa. Sin renunciar a marcar igual que en la Escuela de Niños la verticalidad de la caja de escaleras, la Escuela de Niñas incide en la horizontalidad compositiva: desde las fenêtres a longeur de las fachadas principales, hasta la detallista introducción de las franjas corridas de ladrillo que interrumpen la blancura de los muros enfoscados, la vinculación del edificio al paisaje está marcada por el apego a la tierra y su condición de mirador hacia el valle.

Siguiendo aguas abajo el curso del río, la presencia de la obra de colonización franquista se marca con las presencias puntua- les de otros pueblos, como Maruanas (1964), San Antonio (1960), Encinarejo (1942) y Rivero de Posadas (1953), obras de Francisco Giménez de la Cruz, que debido a la proximidad de la capital cordobesa y a la intensa presión urbanistica reciente, han visto transformado su carácter de manera más o menos acusada al de residencias dormitorio o segundas residencias.

Es necesario, en este punto, hacer mención a cómo la concentración de actividad económica en Córdoba condujo a la instalación de establecimientos industriales que, en su relación con la agricultura, también son muestra de la complejidad y transversalidad de su transformación. En el recorrido de la carretera nacional hacia el suroeste, son fácilmente distinguibles las siluetas de los silos de almacenamiento de la fábrica de pastas Gallo (década de los 60), que tuvo sus orígenes en una instalación harinera que aprovechaba la fuerza del río para garantizar su suministro energético, y que a lo largo de cuatro décadas de crecimiento ha consolidado su presencia como polígono industrial de notable envergadura.

Idéntica notoriedad vertical cobran, en la aproximación a la capital en la antigua carretera nacional, los silos de hormigón de la fábrica de cervezas El Águila (Rafael de la Hoz Arderius y Gerardo Olivares James, 1962), que en su desplazamiento relativo ofrecen una inusitada ligereza al material. Haciendo las veces de reclamo publicitario, adquieren escala territorial en su contraposición suprematista a la estructura horizontal y pragmática de las naves de producción que buscan de manera sorprendente referencias en la extensión de la cercana mezquita catedral para ofrecer claves de posteriores cambios de uso, ampliaciones y modificaciones ligadas al avance de los procesos productivos.

El Águila responde a un tipo de establecimiento industrial que, en la más canónica tendencia de la modernidad, buscaba su asociación a la ciudad; de manera diferente a otros casos, relativamente frecuentes en la primera industrialización de Andalucia, como la fábrica azucarera San Fernando y destilería Los Rosales (1925), en la que la instalación de la industria supuso el origen de una nueva población, los Rosales, prácticamente independiente del núcleo existente de Tocina. Este hecho nos habla por si solo de la escala sublime de este establecimiento, hoy día abandonado y bajo amenaza de desaparición, que en su día constituyó un modelo fabril modélico, cuya inserción está completamente determinada por el territorio: la cercanía del curso del Guadalquivir proporcionaba el agua necesaria para el cultivo y el lavado de la remolacha; las canteras de piedra caliza próximas garantizaban el suministro de cal necesario para los procesos químicos, mientras que la conexión al ferrocarril permitía, diariamente, la entrada de hasta dos mil toneladas de remolacha y la salida de doscientos hectolitros de alcohol conseguidos a través del sistema Barbet.

También la vinculación al territorio es clave para explicar la situación y funcionamiento de la fábrica de harinas y tejidos de yute Sánchez Pastor (1926), en la localidad de Peñaflor, donde se evidencia su lógica de funcionamiento desde el cuerpo más próxi- 

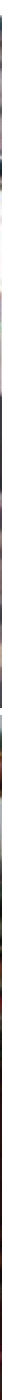

Pueblo de colonización Esquivel (1952). Alcalá del Río, Sevilla. Pueblo de colonización Llanos del Sotillo (1956). Andújar, Jaén.

Fotos: Juan Carlos Cazalla, IAPH

Esquivel en fiestas.

Interior de la iglesia del poblado de Llanos del Sotillo.

Fotos: Juan Carlos Cazalla, IAPH

mo al rí, con la turbina y la bomba del transportador neumático del trigo, al cuerpo intermedio donde se situaban la maquinaria de producción de sémola, harina y derivados, hasta el cuerpo de entrada, que situaba a los almacenes, silos y oficina en inmediata proximidad a la línea de ferrocarril. La fábrica, en estado de abandono, evidencia la racionalidad de su funcionamiento además en la aplicación de tecnologías constructivas avanzadas para la época, como el hormigón armado.

Llegando al término de la ruta, la presencia de Esquivel (19521955), obra del arquitecto Alejandro de la Sota, constituye siempre una referencia sobre los invariantes, aciertos y paradojas de la arquitectura de colonización. Situado junto a la carretera de Villaverde a Alcalá del Río, la disposición radial de su trazado, el protagonismo y especial cuidado de los espacios y edificios públicos que se abren a la carretera, siguen ofreciendo testimonio de la difícil supervivencia de esta arquitectura al paso del tiempo. No obstante, la brillantez del proyecto sigue siendo evidente, a pesar de las transformaciones recientes de viviendas y mobiliario públi$\mathrm{co}$, y reafirma la condición de hito en la colonización, simétrico en nuestro recorrido a Llanos del Sotillo.

El ambicioso proyecto de hacer navegable el Guadalquivir tenía como último salto la presa y central de Alcalá del Río (1928). A diferencia del caso del Carpio, la central forma parte del cuerpo de la presa y se sitúa en la margen derecha del río. La presa, de ocho compuertas móviles sobre pilones separados 15 metros, reinterpreta el racionalismo más austero a través del recurso historicista que hemos señalado en las obras de Fernández Shaw, en este caso, al igual que en el Jándula, a través de la tipología de castillo medieval. Claro ejemplo del uso de este recurso es el artificio del azulejo azul entre los merlones del pretil de la central que pretende evitar la visión de la cubierta a dos aguas de la sala de máquinas.

Al final de esta lectura compleja, podremos entender que el patrimonio que la modernidad lega al campo está constituido por estas muestras de perfeccionamiento, progreso y mejora: presas, poblados, industrias y escuelas que llegan a través de la técnica. Y visto a través de los ojos color turquesa del elefante de vapor de El Carpio, se mostrará no como producto exclusivo de la razón, sino como sueño hecho realidad por la experiencia y la sensibilidad humana. 